ORIGINAL ARTICLE

\title{
Walking Disability in Patients with Pelvic Insufficiency Fracture after Radiotherapy for Uterine Cervical Cancer
}

\author{
Akira Kido, MD, PhD ${ }^{\text {a }}$ Shozo Yoshida, MD, PhD ${ }^{b}$ Emiko Shimoda, MD, PhD ${ }^{\mathrm{c}}$ Yukako Ishida, MD ${ }^{\text {a }}$ \\ Masatoshi Hasegawa, MD, PhD ${ }^{\mathrm{c}}$ Hiroshi Kobayashi, MD, PhD ${ }^{\mathrm{b}}$ Kanya Honoki, MD, PhD ${ }^{\mathrm{d}}$ \\ Hirosei Horikawa, MD, PhD ${ }^{a}$ and Yasuhito Tanaka, MD, $\mathrm{PhD}^{\mathrm{d}}$
}

\begin{abstract}
Objective: Radiotherapy is an essential component of curative or palliative therapy for patients with uterine cervical cancer. Although advances in radiotherapy have led to longer survival, survivors may consequently be at risk of pelvic insufficiency fracture (PIF). We retrospectively reviewed medical records and clinical outcomes to assess the impact of PIF on walking disability. Methods: Between January 2002 and December 2009, 145 uterine cancer patients treated with radiotherapy in our hospital were reviewed. Among these, 15 patients $(10.3 \%)$ were diagnosed with PIF. The types of fractures were identified according to the AO/OTA classification system. Medical records were examined to establish the time to first diagnosis of PIF, the type of fracture, and clinical outcomes. Disability was assessed using Barthel index mobility scores. Results: The median time to PIF detection was 16 months. Of the 15 patients with PIF, 14 had type B fractures (7 cases of B2 and 7 cases of B3) and 1 had a type $\mathrm{C}$ fracture. Among 11 patients with pelvic pain, 6 achieved pain control but 5 patients with bilateral lesions in the posterior arch or lateral compression of the sacrum developed pain that finally resulted in walking disability and a lower performance status. Conclusions: PIF causes severe motor disturbance in patients with unstable fracture types. Routine imaging checkups were useful during the 5 years after completion of radiotherapy; in nine patients the fracture progressed for longer than 1 year. In cancer rehabilitation for PIF patients, continuous assessment is essential for predicting walking disability.
\end{abstract}

Key Words: pelvic insufficiency fracture; radiotherapy; uterine cervical cancer; walking disability

\section{INTRODUCTION}

Radiotherapy is an essential component of both definitive and adjuvant therapy for patients with uterine cervical cancer. ${ }^{1)}$ Advances in radiotherapy have led to longer progression-free survival and overall survival, but survivors may consequently face the risk of pelvic insufficiency fractures (PIFs). ${ }^{1)}$ Whereas PIF was previously considered a minor complication of radiotherapy for uterine cervical cancer, recent studies have found a higher prevalence than was previously thought. $^{2-4)}$ PIFs cause severe pelvic pain and can be extremely detrimental to patients' quality of life. Although several researchers have reported the incidence of radiationinduced PIFs and their risk factors, ${ }^{5-7}$ ) the disabling impact of such injuries on the activities of daily life has thus far been rarely investigated. In this study, we focused on radiationinduced PIFs in patients who had undergone therapy for uterine cervical cancer. A retrospective review was carried out of clinical courses and assessment of the impact of PIFs on walking disability.

Received: July 7, 2016, Accepted: December 6, 2016, Published online: December 21, 2016

${ }^{a}$ Department of Rehabilitation Medicine, Nara Medical University, Kashihara, Nara, Japan

${ }^{b}$ Department of Obstetrics and Gynecology, Nara Medical University, Kashihara, Nara, Japan

${ }^{\mathrm{c}}$ Department of Radiation Oncology, Nara Medical University, Kashihara, Nara, Japan

${ }^{\mathrm{d}}$ Department of Orthopedic Surgery, Nara Medical University, Kashihara, Nara, Japan

Correspondence: Akira Kido, Department of Rehabilitation Medicine, Nara Medical University, 840 Shijo-cho, Kashihara,

Nara 634-8522, Japan Tel: +81 742223051 (ext. 2324) Fax: +81 742256449 E-mail: akirakid@naramed-u.ac.jp

This publication was supported by JSPS KAKENHI Grant Number JP16HP1002.

Copyright (C) 2016 The Japanese Association of Rehabilitation Medicine 
Table 1. Definition of AO-OTA classification of pelvic ring fractures

\begin{tabular}{|c|c|c|c|}
\hline A & \multicolumn{3}{|c|}{ Lesion sparing (or no displacement of) posterior arch } \\
\hline \multirow[t]{10}{*}{ B } & \multicolumn{3}{|c|}{ Incomplete disruption of posterior arch, partially stable } \\
\hline & $\mathrm{B} 1$ & Unila & 1 disruption of posterior arch, external rotation \\
\hline & \multirow[t]{4}{*}{$\mathrm{B} 2$} & \multicolumn{2}{|c|}{ Unilateral, partial disruption of posterior arch, internal rotation } \\
\hline & & B2.1 & Anterior compression fracture of sacrum \\
\hline & & B2.2 & Partial sacroiliac joint fracture/subluxation \\
\hline & & $\mathrm{B} 2.3$ & Incomplete posterior iliac fracture \\
\hline & \multirow[t]{4}{*}{ B3 } & \multicolumn{2}{|c|}{ Bilateral, partial disruption of posterior arch } \\
\hline & & B3.1 & Bilateral B1 \\
\hline & & B3.2 & $\mathrm{B} 1$ and $\mathrm{B} 2$ \\
\hline & & B3.3 & Bilateral B2 \\
\hline $\mathrm{C}$ & \multicolumn{3}{|c|}{ Complete disruption of posterior arch, unstable } \\
\hline
\end{tabular}

\section{PATIENTS AND METHODS}

Between January 2002 and December 2009, 154 women with uterine cervical cancer underwent radiotherapy as primary treatment at Nara Medical University Hospital. The patients received a computed tomography (CT) or magnetic resonance imaging scan every 6 months (during the 2 years after the completion of radiotherapy) or CT every year (during the 5 years after the completion of radiotherapy) as part of the clinical follow-up. All patients received whole pelvic radiotherapy in 2-Gy fractions using $10-\mathrm{MV}$ photons with customized blocking. The median radiotherapy dose was 50 Gy. An anteroposterior parallel opposing-field technique was used. Of the 154 patients, those who were subsequently found to have bone metastases, despite initially being diagnosed with PIF, were excluded from the analysis. Consequently, 145 patients were eligible for analysis. Medical records indicated that 15 of 145 patients $(10.3 \%)$ had a diagnosis of PIF. Clinical characteristics, including age, body mass index (BMI), weight, menopausal state, and dose of radiotherapy were examined in PIF and non-PIF patients. Comparisons of the variables between groups were performed with the chi-square test or Mann Whitney U test. P-values of less than 0.05 were considered significant. All statistical analyses were performed with SPSS 16.0 for Windows (SPSS Inc., Chicago, Il, USA). The type of fracture was identified according to the AO/OTA (pelvic ring) classification system (Table 1) ${ }^{8)}$ Medical records were examined to establish the time to first diagnosis of PIF, types of fractures, and impact on walking disability. Disability was assessed using Barthel index (BI) mobility scores. ${ }^{9)}$ The four-category verbal rating scale (VRS-4) ${ }^{10,11)}$ was used for assessment of pain at the time of diagnosis of PIF. Informed consent for publication was obtained from the patients, and this study was approved by the ethics committee in our institute.

\section{RESULTS}

\section{Patient Characteristics}

The mean age of PIF patients was higher than that of nonPIF patients (69.8 vs 62.1 years, $\mathrm{P}=0.047$ ). There were no significant differences in BMIs, body weights, and radiation doses. The details and types of fractures are shown in Table 2. The median time to detection of PIF was 16 months (range, 4-36 months). In nine patients, the fracture progressed for between 1 and 2 years. Among the 15 consecutive patients with PIFs, type B2/B3 fractures were found in 14 patients and type $\mathrm{C}$ in 1 patient. Of the 11 patients who had pain, 6 experienced symptom improvement with sufficient pain control, whereas the remaining 5 had walking disabilities (BI mobility scores of 5 and 10). Among the five disabled patients, four had bilateral lesions in the posterior arch of the pelvis (type B3 and type C). The other disabled patient had unilateral lesions in the posterior arch (type B2) with lateral compression of the sacrum. Opioids were prescribed to four patients who did not achieve pain relief with nonsteroidal anti-inflammatory drugs (NSAIDs); however, weight-bearing pain was not controlled even with pelvic orthosis (Table 2).

\section{Walking Disability and Fracture Types}

Table 3 shows relationships between fracture types and BI mobility scores. Interestingly, patients with bilateral fracture types B3 and $\mathrm{C}$ had a high incidence of walking disability (four out of five; 80\%). Figure 1 shows representative images of a disabled patient with PIF (patient \#9) in whom unstable, complete disruption of the posterior arch was found. At the 
Table 2. Patient characteristics

\begin{tabular}{|c|c|c|c|c|c|c|c|c|c|c|c|}
\hline Pt. no. & $\begin{array}{c}\text { Age } \\
\text { (years) }\end{array}$ & Gy & $\begin{array}{l}\text { Time to first } \\
\text { diagnosis of PIF } \\
\text { (months) }\end{array}$ & $\begin{array}{c}\text { Fracture } \\
\text { type }\end{array}$ & $\begin{array}{c}\text { Lateral } \\
\text { compression } \\
\text { of sacrum }\end{array}$ & VRS-4 & NSAIDs & Opioids & Orthosis & $\begin{array}{l}\text { Pain } \\
\text { relief }\end{array}$ & $\begin{array}{l}\text { Mobility } \\
\text { Score (BI) }\end{array}$ \\
\hline 1 & 74 & 50 & 9 & B2.2 & & 1 & + & & & + & 15 \\
\hline 2 & 49 & 50 & 15 & B2.1 & & 0 & & & & & 15 \\
\hline 3 & 54 & 50 & 10 & B3.3 & & 0 & & & & & 15 \\
\hline 4 & 88 & 50 & 31 & B3.3 & & 0 & & & & & 15 \\
\hline 5 & 84 & 60 & 12 & B3.2 & & 1 & + & & & + & 15 \\
\hline 6 & 85 & 50 & 27 & B3.2 & & 1 & + & & + & + & 10 \\
\hline 7 & 73 & 50 & 4 & B2.3 & + & 1 & + & + & + & & 5 \\
\hline 8 & 73 & 60 & 16 & B3.1 & & 0 & & & & & 15 \\
\hline 9 & 65 & 50 & 21 & $\mathrm{C} 2.1$ & + & 2 & + & + & + & & 5 \\
\hline 10 & 79 & 60 & 11 & B2.3 & & 1 & + & & & + & 15 \\
\hline 11 & 63 & 50 & 36 & B2.3 & & 1 & + & & & + & 15 \\
\hline 12 & 64 & 50 & 26 & B2.3 & & 1 & + & & & + & 15 \\
\hline 13 & 61 & 50 & 27 & B3.3 & + & 2 & + & + & + & & 10 \\
\hline 14 & 77 & 50 & 17 & B3.3 & + & 2 & + & + & + & & 10 \\
\hline 15 & 57 & 50 & 12 & B2.1 & & 1 & + & & & & 15 \\
\hline
\end{tabular}

Table 3. Walking disability and fracture types (number of patients)

\begin{tabular}{llccc}
\hline & \multicolumn{4}{c}{ Barthel index mobility score } \\
\cline { 2 - 5 } Fracture type & 0 & 5 & 10 & 15 \\
\hline B2.1 & 0 & 0 & 0 & 2 \\
B2.2 & 0 & 0 & 0 & 1 \\
B2.3 & 0 & 1 & 0 & 3 \\
B3.1 (bilateral B1) & 0 & 0 & 0 & 1 \\
B3.2 (B1and B2) & 0 & 0 & 1 & 1 \\
B3.3 (bilateral B2) & 0 & 0 & 2 & 2 \\
C2.1 & 0 & 1 & 0 & 0 \\
\hline
\end{tabular}

most recent checkup she was totally free of cancer but, while independent, needed a wheelchair (mobility BI score $=5$ ). She stated that she would have preferred to die of cancer had she known of the disability that followed "curative" radiotherapy.

\section{DISCUSSION}

PIF has in the past been regarded as a minor complication of radiotherapy; however, recent studies have reported a high incidence of PIF $(8.2 \%-36.9 \%)$ after pelvic radiotherapy. ${ }^{2,11-14)}$ Advanced age, ${ }^{3,7)}$ low body weight, ${ }^{3)}$ low BMI, ${ }^{6}$ and postmenopausal status ${ }^{7)}$ have been reported as risk factors for PIF after radiotherapy.

In various reports, PIFs in most symptomatic patients fully resolves after conservative treatment using analgesics and rest. ${ }^{5,12,13)}$ However, some patients require hospitalization because of severe pain and disability. ${ }^{3,5)}$ Unfortunately, the clinical features of such disabled patients have rarely been investigated. In nine cases of our series, the fracture progressed for between 1 and 2 years. Considering that a median time of 16 months elapsed before the first diagnosis of PIF, the routine 5 years of follow-up can be useful not only for oncological surveys but also for PIF checkups.

In this study, we primarily focused on the disability caused by PIF after radiotherapy in patients with uterine cervical cancer. Radiological findings of lateral compression of the sacrum or bilateral fracture of the posterior arch indicated a high risk of walking disability. In contrast, most patients with unilateral fractures eventually recovered without walk- 

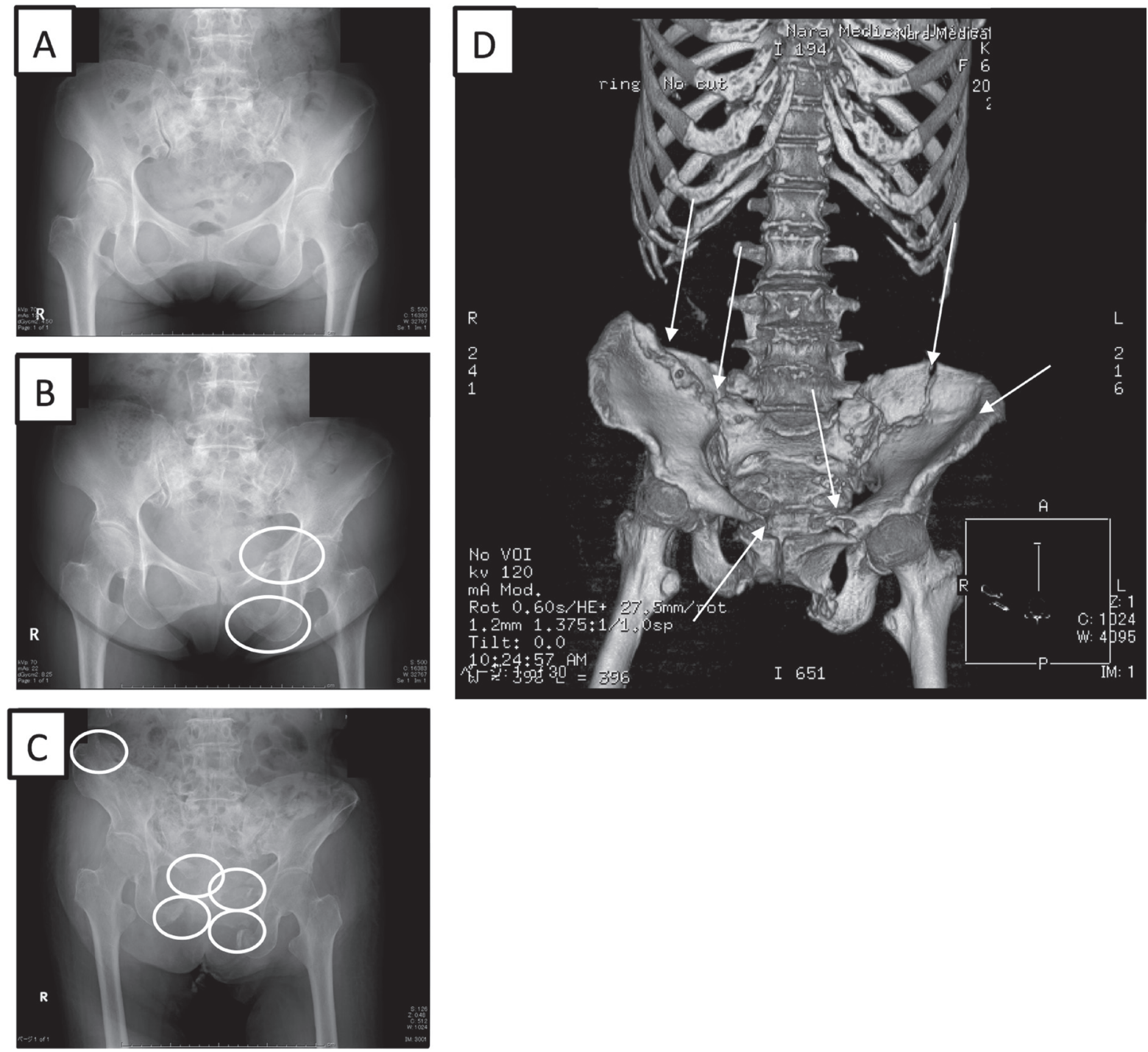

Fig. 1. (A-C) Radiographs of patient no. 9 with a massive PIF. The patient presented with pubic pain 9 months after completion of radiotherapy (A). Unilateral disruption of the pubis (circled) was found 11 months after radiotherapy (B), and complete disruption (circled) was found at 15 months (C). A CT scan at 15 months after radiotherapy showed detailed disruption patterns (arrows) in the pelvic arch (D). Ultimately the patient required the use of a wheelchair but remained independent (BI mobility score $=5$ ).

ing impairment. High-dose radiation affects bone quality, resulting in biological and/or structural weakness of bone. ${ }^{15)}$ Bilateral collapse of the posterior pelvic arch may reflect the extent of impaired bone and result in accelerated skeletal instability, culminating in difficulty in walking. Unfortunately, for these patients, opioids and/or orthosis did not improve walking ability because of the skeletal instability resulting from radiation osteopathy.

For goal setting in cancer rehabilitation with PIF patients, radiological assessment is essential for predicting walking disability. The incidence of PIF in uterine cervical cancer patients is much higher than was once believed. Novel diagnostic strategies are required for cancer survivors, especially to evaluate impaired bone after definitive radiotherapy.

\section{ACKNOWLEDGEMENTS}

This work was supported by JSPS KAKENHI grant number 15K01381, 24592241. 


\section{CONFLICTS OF INTEREST}

The authors declare that there are no conflicts of interest.

\section{REFERENCES}

1. Huh SJ, Kim B, Kang MK, Lee JE, Lim DH, Park W, Shin SS, Ahn YC: Pelvic insufficiency fracture after pelvic irradiation in uterine cervix cancer. Gynecol Oncol 2002;86:264-268. [Medline] [CrossRef]

2. Kwon JW, Huh SJ, Yoon YC, Choi SH, Jung JY, Oh $\mathrm{D}$, Choe BK: Pelvic bone complications after radiation therapy of uterine cervical cancer: evaluation with MRI. AJR Am J Roentgenol 2008;191:987-994. [Medline] [CrossRef]

3. Tokumaru S, Toita T, Oguchi M, Ohno T, Kato S, Niibe Y, Kazumoto T, Kodaira T, Kataoka M, Shikama N, Kenjo M, Yamauchi C, Suzuki O, Sakurai H, Teshima T, Kagami Y, Nakano T, Hiraoka M, Mitsuhashi N, Kudo S: Insufficiency fractures after pelvic radiation therapy for uterine cervical cancer: an analysis of subjects in a prospective multi-institutional trial, and cooperative study of the Japan Radiation Oncology Group (JAROG) and Japanese Radiation Oncology Study Group (JROSG). Int J Radiat Oncol Biol Phys 2012;84:e195-e200. [Medline] [CrossRef]

4. Mehmood Q, Beardwood M, Swindell R, Greenhalgh S, Wareham T, Barraclough L, Livsey J, Davidson SE: Insufficiency fractures in patients treated with pelvic radiotherapy and chemotherapy for uterine and cervical cancer. Eur J Cancer Care (Engl) 2014;23:43-50. [Medline] [CrossRef]

5. Oh D, Huh SJ, Nam H, Park W, Han Y, Lim DH, Ahn YC, Lee JW, Kim BG, Bae DS, Lee JH: Pelvic insufficiency fracture after pelvic radiotherapy for cervical cancer: analysis of risk factors. Int J Radiat Oncol Biol Phys 2008;70:1183-1188. [Medline] [CrossRef]

6. Schmeler KM, Jhingran A, Iyer RB, Sun CC, Eifel PJ, Soliman PT, Ramirez PT, Frumovitz M, Bodurka DC, Sood AK: Pelvic fractures after radiotherapy for cervical cancer: implications for survivors. Cancer 2010;116:625-630. [Medline] [CrossRef]
7. Uezono H, Tsujino K, Moriki K, Nagano F, Ota Y, Sasaki R, Soejima T: Pelvic insufficiency fracture after definitive radiotherapy for uterine cervical cancer: retrospective analysis of risk factors. J Radiat Res (Tokyo) 2013;54:1102-1109. [Medline] [CrossRef]

8. Marsh JL, Slongo TF, Agel J, Broderick JS, Creevey W, DeCoster TA, Prokuski L, Sirkin MS, Ziran B, Henley B, Audigé L: Pelvis. In Fracture and Dislocation Classification Compendium - 2007:Orthopaedic Trauma Association Classification, Database and Outcomes Committee. J Orthop Trauma 10 suppl 2007; S59-67.

9. Mahoney FI, Barthel DW: Functional evaluation: the Barthel Index. Md State Med J 1965;14:61-65. [Medline]

10. Hartrick CT: A four-category verbal rating scale (VRS4), an 11-point numeric rating scale (NRS-11), and a 100-mm visual analog scale (VAS) were compared in the assessment of acute pain after oral surgery. Clin J Pain 2001;17:104-105. [Medline] [CrossRef]

11. Gagliese L, Weizblit N, Ellis W, Chan VW: The measurement of postoperative pain: a comparison of intensity scales in younger and older surgical patients. Pain 2005;117:412-420. [Medline] [CrossRef]

12. Ogino I, Okamoto N, Ono Y, Kitamura T, Nakayama $\mathrm{H}$ : Pelvic insufficiency fractures in postmenopausal woman with advanced cervical cancer treated by radiotherapy. Radiother Oncol 2003;68:61-67. [Medline] [CrossRef]

13. Ikushima H, Osaki K, Furutani S, Yamashita K, Kishida Y, Kudoh T, Nishitani H: Pelvic bone complications following radiation therapy of gynecologic malignancies: clinical evaluation of radiation-induced pelvic insufficiency fractures. Gynecol Oncol 2006;103:1100 1104. [Medline] [CrossRef]

14. Baxter NN, Habermann EB, Tepper JE, Durham SB, Virnig BA: Risk of pelvic fractures in older women following pelvic irradiation. JAMA 2005;294:2587-2593. [Medline] [CrossRef]

15. Oh D, Huh SJ: Insufficiency fracture after radiation therapy. Radiat Oncol J 2014;32:213-220. [Medline] [CrossRef] 